\title{
Modifying Mg/Al Composite Catalyst for \\ Preparing Narrow-range Distribution Polyether
}

\author{
Bing Pan, Xiujun Liu, Shuangheng Ma, Bin Wang \\ Department of Material Science and Chemical Engineering \\ Tianjin Polytechnic University, Tianjin 300160, China \\ Tel: 86-22-24584562 E-mail: panbing1860@126.com
}

The research is financed by the science and technology development foundational project of Tianjin higher institute. (Grant number: 20050702).

\begin{abstract}
The modifying $\mathrm{Mg} / \mathrm{Al}$ composite catalyst was prepared by co-precipitation method and it was characterized by FTIR and BET. It was used in the ethoxylation between ethanls and EO, and the narrow-range distribution polyethers which have steady properties were prepared. The product was characterized by FTIR and GC/MS. The molecular weight distribution of the product can arrive to $83.28 \%$.
\end{abstract}

Keywords: Narrow-range distribution, Ethoxylation, Polyether

\section{Introduction}

The ethoxylation of aliphatic alcohol depicted in Scheme 1 has been utilized for the commercial production of non-ionic surfactants. Similar types of ethoxylations for other organic compounds having active hydrogens have been also applied in the production of various wetting and emulsifying agents (Daehwan Kima, Chengzhe Huang, \& Hongsun Lee, 2003:229).

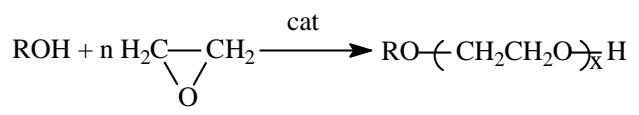

Scheme 1. ethoxylation of aliphatic alcohol. R: long-chain alkyl group, n: mole ratio of EO/ROH, $\mathrm{x}$ : number of ethoxylene units in product mixture.

It is well known that polyether has the superior properties of nontoxicity, flexibility, hydrophilicity, and biocompatibility These properties are very useful for a polymer used as a drug delivery system (Shaobing Zhou, Xianmo Deng, \& Hua Yang, 2003:3566). In recent years, the synthesis of polyester-polyether type block copolymer has attracted much attention, because they can be used in future medical applications in implantation and wound treatment, and as controlledrelease drug carriers (Suh H, Jeong BM, \& Rathi R, 1998:336; Jeong BM, Bae YH, \& Lee DS, 1997:860; Choi SW, Choi SY, \& Jeong BM, 1999:2305).

A great number of patents have recently been published dealing with catalytic systems promoting narrow-range ethoxylation (NRE), i.e. ethoxylation of fatty alcohols with a narrow distribution of the molecular weights of the ethoxylated oligomers and containing a very low concentration of the residual unreacted alcohol. Products of this type have better properties than those produced with the traditional alkaline catalyst $\mathrm{KOH}$ and for low ethylene oxide/substrate molar ratio, can be sulphonated without forming undesired dioxane (M. Di Serio, P. Iengo, \& R. Gobetto 1996:240). In the ethoxylations of aliphatic alcohols, homogeneous basic catalysts, such as $\mathrm{NaOH}, \mathrm{KOH}$ or $\mathrm{NaOCH}_{3}$, are generally used to facilitate EO insertion to the alcohols at relatively low temperature and pressure. In this homogeneous type of alcohol ethoxylation, distributions of oxyethylene units in the ethoxylated product mixture are much broader than the statistical Poisson-type distribution. R. Improta had used Aluminium alkoxide sulphate catalysts to promote ethoxylation of fatty alcohols with a narrow distribution of the molecular weights (R. Improta, M. Di Serio and E. Santacesaria, 1999:170).

Hydrotalcite-type solids have been investigated as one group of catalytic materials for the narrow-range oxyethylation of aliphatic alcohols and esters (Mckenzite A L, Fishel C T, \& Davis R J, 1992:548; Rao K K, Gravelle M, 1998:115). 
Hydrotalcite-type materials are a class of synthetic mixed metal layered hydroxides, generally described by the formula $\left[\mathrm{M}_{1-\mathrm{x}}{ }^{2+} \mathrm{M}_{\mathrm{x}}{ }^{3+}(\mathrm{OH})_{2}\right]\left[\mathrm{A}_{\mathrm{x} / \mathrm{m}}{ }^{\mathrm{m}-} \cdot \mathrm{nH}_{2} \mathrm{O}\right]$, where $\mathrm{x}$ may vary from 0.17 to 0.33 depending on the particular combination of divalent $\mathrm{M}^{2+}$ and trivalent $\mathrm{M}^{3+}$ ions. $\mathrm{A}^{\mathrm{m}-}$ represents the m-valent anion necessary to compensate the positive charge of brucite-like hydroxide layer and locates between mixed metal hydroxide layers (Daehwan Kima, Chengzhe Huang, \& Hongsun Lee, 2003:231).

In this paper, we prepared the modified hydrotalcite-type catalysts and report its catalytic properties in ethanol ethoxylation. Otherwise, we characterized the catalyst and product.

\section{Experimental}

\subsection{Materials}

Ethanol, $\mathrm{Na}_{2} \mathrm{CO}_{3}, \mathrm{Mg}\left(\mathrm{NO}_{3}\right)_{2} \cdot 6 \mathrm{H}_{2} \mathrm{O}, \mathrm{Al}\left(\mathrm{NO}_{3}\right)_{3} \cdot 9 \mathrm{H}_{2} \mathrm{O}$ and $\mathrm{Co}\left(\mathrm{NO}_{3}\right)_{2} \cdot 6 \mathrm{H}_{2} \mathrm{O}$, were of reagent grade and were purchased from Tianjin Chemistry regent Co. (China). EO of $99.9 \%$ was supplied from China Petroleum Chem. Co.

\section{2 the preparation of $\mathrm{Mg} / \mathrm{Al}$ composite catalyst}

Hydrotalcit-type material was prepared by co-precipitation method at 60 ? with water-heating method. $\mathrm{Na}_{2} \mathrm{CO}_{3}$ solution in $500 \mathrm{ml}$ beaker was added mixed solution of $\mathrm{Mg}\left(\mathrm{NO}_{3}\right)_{2} \cdot 6 \mathrm{H}_{2} \mathrm{O}, \mathrm{Al}\left(\mathrm{NO}_{3}\right)_{3} \cdot 9 \mathrm{H}_{2} \mathrm{O}$ and $\mathrm{Co}\left(\mathrm{NO}_{3}\right)_{2} \cdot 6 \mathrm{H}_{2} \mathrm{O}$ which with 15:5:1 ratio of $\mathrm{Mg} / \mathrm{Al} / \mathrm{Co}$ components with strong mixing and stirring for $1 \mathrm{~h} ; \mathrm{pH}$ 8-9 was maintained during the co-precipitation reaction. The white cake was isolated by filtration of the suspension and washed five times with distilled water. The cake was dried for $12 \mathrm{~h}$ in air circulating oven at 100 ? to give white powder and then heated in the tubular stove at 500 ? for $5 \mathrm{~h}$, at last the catalyst was got.

\section{3 ethoxylation}

Ethoxylation was performed in membrane reactor. The reactor was equipped with a tubular $\mathrm{Al}_{2} \mathrm{O}_{3}$ ceramic membrane which length is $120 \mathrm{~mm}$ and diameter is $12 \mathrm{~mm}$. The catalyst was $1 \mathrm{~g}$ which was put in the reactor. Ethanol is $1 \mathrm{ml} / \mathrm{h}$ which was supplied by a piston pump. EO was supplied to the reactor by opening the needle vavle of the EO storage chamber and its velocity was controlled by a rotameter. The reaction was processed at 110 ?

\subsection{Product analysis}

Liquid product was separated by filtration of crude produce and was analyzed using FTIR and GC/MS.

\section{Results and discussion}

\subsection{Characterization of the catalyst}

Adding a third metal ion into the complex was to adjust the pore size of catalysts. There is a three-tier electron out of Co

${ }^{2+}$ ions so that its volume is bigger than $\mathrm{Mg}^{2+}$ ions. $\mathrm{Co}^{2+}$ ions were embedded into hydrotalcite structure to adjust the pore size and lead to the hydrotalcite surface lattice defects. After calcination its surface would form a large number of nano-pores and huge amounts of alkaline center which are helpful to the latter reaction.

Figure1shows power IR patterns of the $\mathrm{Mg} / \mathrm{Al}$ and $\mathrm{Mg} / \mathrm{Al} / \mathrm{Co}$ composite catalyst. The IR patterns of two samples are almost identical. The position of $885 \mathrm{~cm}^{-1}, 744 \mathrm{~cm}^{-1}$ is the absorption proportion of metal-oxygen bond. It shows that the entry of $\mathrm{Co}^{2+}$ has enter into don't change the crystalline structure.

The specific surface area of modification $\mathrm{Mg} / \mathrm{Al}$ composite catalyst is $135.8 \mathrm{~m}^{2} / \mathrm{g}$. High specific surface area is useful for the touch between reactants and alkaline center of the catalyst surface so that the exthoxylation is accelerated.

\subsection{Analysis of polyether}

Figure 2 shows the IR curve of the product. From the figure 2 we can see the characteristic absorption band: the position of $3401 \mathrm{~cm}^{-1}$ is hydroxyl; the position of $2925 \mathrm{~cm}^{-1}, 2858 \mathrm{~cm}^{-1}, 1458 \mathrm{~cm}^{-1}$ are methyl, the stretching vibration and rocking vibration band of methylene respectively and the position of $1112 \mathrm{~cm}^{-1}$ is the C-O-C bond skeleton vibration.

The product has been analyzed by the GC/MS. The results show that the selectivity of object product comes to $83.28 \%$ which is high than $\mathrm{KOH}$ as the catalyst.

\section{Conclusions}

The modifying $\mathrm{Mg} / \mathrm{Al}$ composite catalyst was prepared which is very active for narrow-range ethoxylation of ethanol. The products are narrow-range, high purity and light color which have excellent performance in application. From analysis of the product, the selectivity of object product comes to $83.28 \%$.

\section{References}

Choi, SW, Choi, SY, \& Jeong, BM. (1999). Thermoreversible gelation of poly(ethylene oxide) biodegradable polyester block copolymers. J Polym Sci A. 37(14), pp. 2305-2317. 


\section{Modern Applied Science}

Daehwan, Kima, Huang, Chengzhe \& Hongsun Lee. (2003). Hydrotalcite-type catalysts for narrow-range oxyethylation of 1-dodecanol using ethyleneoxide. Applied catalysis A: General. 249(2), pp. 229-240.

Jeong, BM, Bae, YH, \& Lee, DS. (1997). Biodegradable blocks copolymers as injectable druf-delivery system. Nature. 338, pp. 860-862.

M. Di Serio, P. Iengo, \& R. Gobetto (1996). Ethoxylation of fatty alcohols promoted by an aluminum alkoxide sulphate catalyst. Journal of Molecular Catalysis A: Chemical. 112(2), pp. 235-251.

Mckenzite A L, Fishel C T, \& Davis R J. (1992). Investigation of the surface structure and basic properties of calcined hydrotalcites. J Catal. 138(2), pp. 548-560.

R. Improta, M. Di Serio, \& E. Santacesaria. (1999). Aluminium alkoxide sulphate catalyst: a computational study. Journal of Molecular Catalysis A: Chemical. 137(1-3), pp. 169-182.

Rao K K, \& Gravelle M. (1998). Activation of Mg-A1 hydrotacite catalyst for aldol condensation reaction. J Catal. 173, pp. 115-121.

Suh, H, Jeong, BM, \& Rathi, R. (1998). Regulation of smooth muscle cell proliferation using paclitaxel-loaded poly (ethylene oxide)-poly (lactide/glycolide)nanospheres. Biomed J Mater Res. 42(2), pp. 331-338.

Zhou, Shaobing, Deng, Xianmo \& Yang, Hua. (2003). Biodegradable poly (e-caprolactone)-poly (ethylene glycol) blocks copolymers: characterization and their use as drug carriers for a controlled delivery system. Biomaterials. 24(3), pp. 3563-3570.

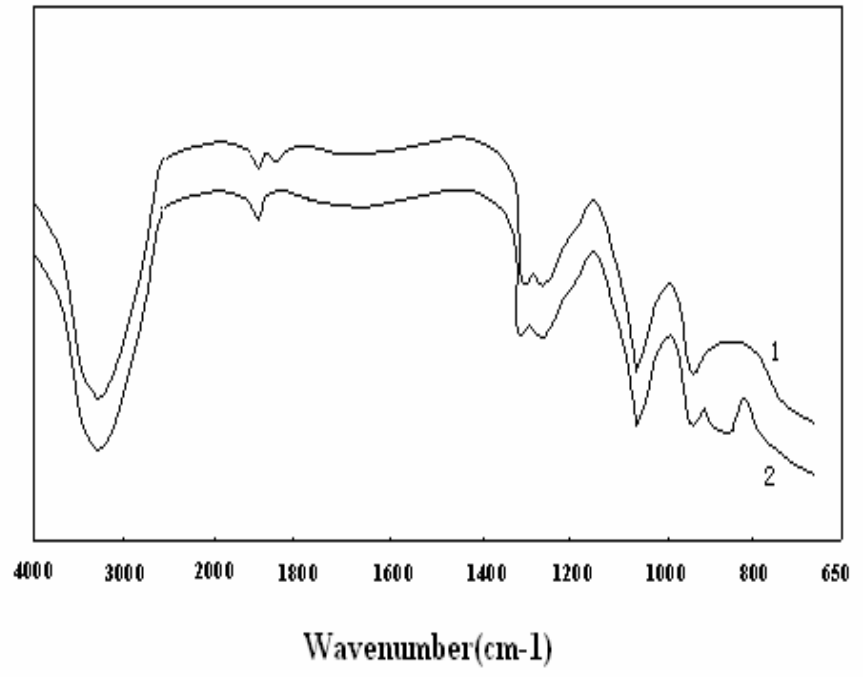

Figure 1. FT-IR adsorption spectra of (1) $\mathrm{Mg} / \mathrm{Al}$, (2) $\mathrm{Mg} / \mathrm{Al} / \mathrm{Co}$

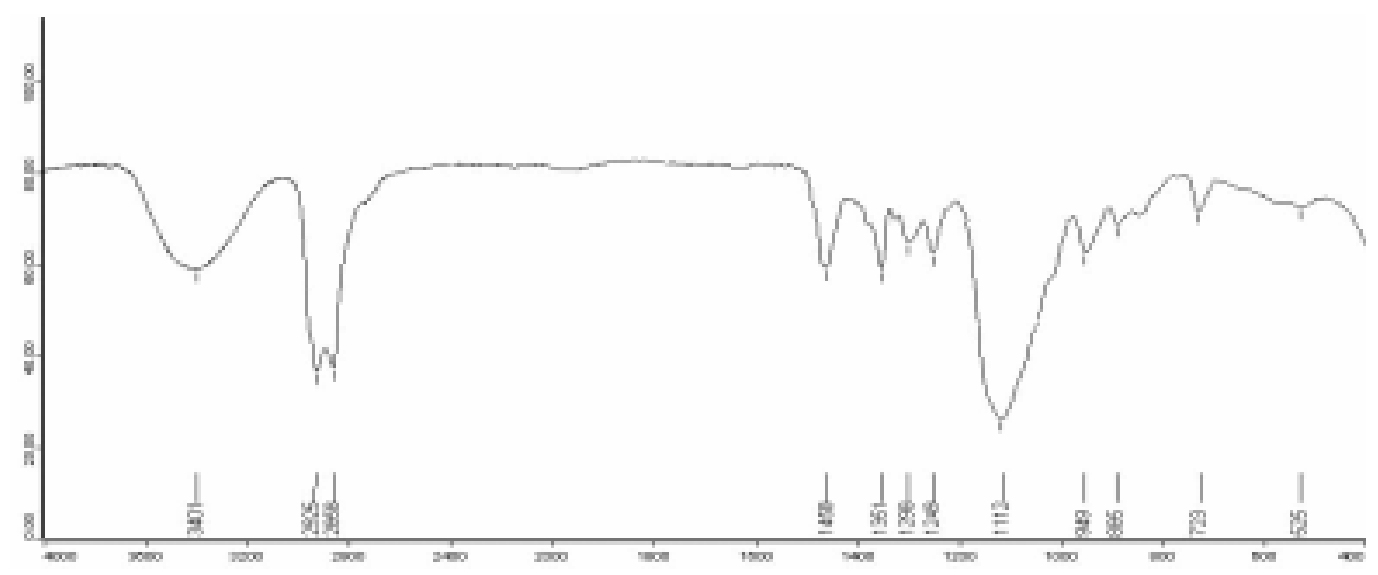

Figure 2. FT-IR spectra of the product 